\title{
Extrahepatic Bile Duct Mucoepidermoid Carcinoma
}

National Cancer Institute

\section{Source}

National Cancer Institute. Extrahepatic Bile Duct Mucoepidermoid Carcinoma. NCI

Thesaurus. Code C5862.

A mucoepidermoid carcinoma that arises from the extrahepatic bile ducts. 